\title{
Centella asiatica prevents chronic unpredictable mild stress-induced behavioral changes in rats
}

\author{
Saravanan Jagadeesan ${ }^{1,2}$, Samaila Musa Chiroma1,3 , Mohamad Taufik Hidayat Baharuldin ${ }^{\text {, }}$ \\ Che Norma Mat Taib ${ }^{1}$, Zulkhairi Amom ${ }^{4}$, Mohd Ilham Adenan ${ }^{5}$, Mohamad Aris Mohd Moklas ${ }^{1, *}$
}

\begin{abstract}
${ }^{1}$ Department of Human Anatomy, Faculty of Medicine and Health Sciences, Universiti Putra Malaysia, 43400 Serdang, Selangor, Malaysia

${ }^{2}$ Department of Human Anatomy, Universiti Tunku Abdul Rahman (UTAR), 43000 Bandar Sungai Long Cheras, Selangor, Malaysia
\end{abstract}

${ }^{3}$ Department of Human Anatomy, Faculty of Basic Medical Sciences, University of Maiduguri, 600230 Maiduguri, Borno State, Nigeria

${ }^{4}$ Faculty of Health Sciences, Universiti Teknologi Mara (UiTM) Kampus Puncak Alam, 42300 Bandar Puncak Alam, Selangor, Malaysia

${ }^{5}$ Atta-ur-Rahman Institute for Natural Product Discovery, Universiti Teknologi Mara (UiTM) Kampus Puncak Alam, 42300 Bandar Puncak Alam, Selangor, Malaysia

\section{Correspondence}

Mohamad Aris Mohd Moklas

Department of Human Anatomy, Faculty of Medicine and Health Sciences,

Universiti Putra Malaysia, 43400

Serdang, Selangor, Malaysia

Email: aris@upm.edu.my

History

- Received: Mar 28, 2019

- Accepted: Jun 11, 2019

- Published: Jun 29, 2019

DOI :

https://doi.org/10.15419/bmrat.v6i6.550

\section{Check for updates}

\section{Copyright}

(C) Biomedpress. This is an openaccess article distributed under the terms of the Creative Commons Attribution 4.0 International license.

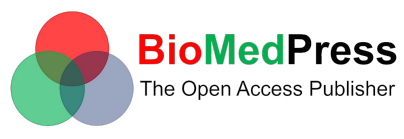

\begin{abstract}
Background: Depression is a psychological disorder which is associated with mood swings and cognitive deficits, and is ranked third among the leading causes of global health care burden. Chronic unpredictable mild stress (CUMS) has been shown to induce depression-like behaviors in rodents, which exhibit similarities to the human form of depression. Centella asiatica (CA) is an ancient medicinal plant which has neuroprotective potential. This work aimed to assess the protective role of CA on CUMS-induced rats. Methods: Thirty six rats randomly divided into six groups were used for the evaluation. The groups were as follows: 1, Unstressed + normal saline (control); 2, CUMS + normal saline (model); 3, CUMS + fluoxetine $(10 \mathrm{mg} / \mathrm{kg}$ ) standard antidepressant; 4-6, CUMS + CA (200, $400 \& 800 \mathrm{mg} / \mathrm{kg}$ ). Nine different stressors (S) (S1: 24-h food deprivation, S2: 24h water deprivation, S3: 5-min cold swimming (at $5^{\circ} \mathrm{C}$ ), S4: 12-h change of cage mate, S5: 1-min tail pinch ( $1 \mathrm{~cm}$ from the tip of the tail), S6: 12-h cage tilt (at $\left.45^{\circ}\right), 57: 12-$ h overcrowding of cage, S8: 12-h wet bedding with $200 \mathrm{~mL}$ of water, and S9: 4-h physical restraint) were administered to the stressed groups with at least 2 stressors per day. The treatments lasted for 8 weeks, and the rats were evaluated through open field test (OFT) and elevated plus maze (EPM) for anxiety-like behavior, forced swimming test (FST) for depression-like behaviour, and T-maze spontaneous alternation for learning and memory. Furthermore, serum cortisol levels were also evaluated. Results: CUMS-induced rats showed anxiety-like behaviors in OFT and EPM tests, depression-like behavior in FST and cognitive deficits in T-maze test, as well as increased serum cortisol levels. Conversely, administration of CA (at 400 and $800 \mathrm{mg} / \mathrm{kg}$ doses) and fluoxetine (at $10 \mathrm{mg} / \mathrm{kg}$ dose) prevented the aberrant behavioral changes and also the changes in the serum cortisol levels. No significant differences of behaviors were observed between the groups of rats administered with CA (400 and $800 \mathrm{mg} / \mathrm{kg}$ ) and those administered with fluoxetine $(10 \mathrm{mg} / \mathrm{kg})$, suggesting that the therapeutic potential of CA is comparable to that of fluoxetine. Conclusion: The data obtained showed that CA, at doses of 400 and $800 \mathrm{mg} / \mathrm{kg}$, effectively reversed the anxiety and depression-like behaviors, amnesic behaviors, as well as serum cortisol levels in a CUMS-induced rat model of depression. This suggests that CA is a potential candidate for the development of future anti-depressants.
\end{abstract}

Key words: Centella asiatica, anxiety, depression, chronic stress, fluoxetine, cognitive deficits, behavioural tests, forced swimming test, cortisol

\section{INTRODUCTION}

Depression is a major public health challenge and is ranked third among the top three foremost causes of global health care burden globally ${ }^{1}$. Besides the mood disorders that are exhibited by depressed patients, cognitive impairments (such as difficulty in decision-making, memory deficits difficulty in learning, and loss of cognitive flexibility) have also been reported ${ }^{2,3}$. Accumulating evidence have shown that these cognitive insufficiencies could be an early occurrence in depression and could help predict the probability of recovery ${ }^{4}$.

Chronic stress is one of the significant contributory factors for various neurological disorders, such as depression and anxiety, and plays a key role leading to cognitive impairments in neurodegenerative diseases ${ }^{5,6}$. The chronic unpredictable mild stress (CUMS) protocol is a classic method that has been used to induce depression-like behaviors and cognitive deficits in rat models and also to study the underlying mechanisms ${ }^{7}$. Since the hippocampus is sensitive to CUMS, impairments of hippocampal structure and functions, such as mental and cognitive deficits, are exhibited by rats which are exposed to the CUMS protocol ${ }^{8}$. Preclinical studies have shown decreased expression of brain-derived neurotrophic factor (BDNF), altered synaptic morphology, and reduced neurogenesis in the hippocampus of rats which 
were exposed to CUMS $^{9}$. Previous researches have shown that when rats are exposed to chronic restraint or chronic mild stress, they exhibit cognitive dysfunction, depletion of BDNF and cAMP-response element binding protein (CREB), and dendritic atrophy of the cornus ammonis 3 (CA3) sub-region of the hippocampus ${ }^{10,11}$.

Centella asiatica (CA) (L.) Urban, of the family Apiaceae, also known as Brahmi or Mandookaparni in Ayurvedic medicine ${ }^{12}$. It is also known as Indian pennyworth in the United States of America (USA), Gotu Kola in Indonesia and Pegaga in Malaysia ${ }^{13}$. CA grows extensively in shady, marshy, damp and wet places, such as paddy fields and river banks ${ }^{14}$. CA is a slender, creeping plant with rooting at the nodes and growing among the damp areas in tropical countries ${ }^{15}$. CA is a faintly aromatic, creeper herb which grows perennially, attaining the height of $15 \mathrm{~cm}(6$ inches) with a glabrous stem. The plant grows well on loamy soil ${ }^{16}$. The reniform shaped leaves grow from the nodes on the stem and measure $1.5-5 \mathrm{~cm}$ in width and $2-6 \mathrm{~cm}$ in length, with flowers which appear as fascicled umbels ${ }^{14}$.

In Ayurvedic medicine, CA is regarded as a rejuvenating herb and as a neurotonic known to increase intelligence and memory ${ }^{12}$. In addition to its neurorejuvenating properties, CA is also used for its psychoactive medicinal properties, such as in the treatment of anxiety in Ayurvedic medicine ${ }^{17}$. The triterpenoid glycosides, including madecassic acid, asiatic acid, madecassoside, and asiaticoside, are the most active compounds isolated from $\mathrm{CA}^{18}$. The whole plant can be used for medicinal purposes, while the nutritive value remains the same for all parts of the plant ${ }^{19}$. As a nutritive supplement, CA has been used for the treatment of sleep disorders in patients with mental health problems. Further, 70\% hydro-ethanolic extract of CA has shown to reduce stress phenomenon and attenuate anxiety-related disorders, as documented in a clinical study ${ }^{20}$. Various preclinical studies to evaluate the properties of CA have demonstrated that it has antioxidant ${ }^{21}$, antiacetylcholinesterase, and anti-apoptotic ${ }^{21,22}$ properties, as well as neuroprotective effects, besides amelioration of learning and memory deficits ${ }^{23,24}$. While asiaticoside in the methanolic extract of CA has been demonstrated to have anxiolytic effects in acutely stressed animals ${ }^{25,26}$ and in chronically immobilized stressed-induced anxiety models ${ }^{27}$, no studies have been conducted as of yet to discern the effects of CA on anxiety, depression-like behaviors, and cognitive deficits in CUMS-induced rats.
The present study evaluated the anxiolytic, antidepressant, and anti-amnesic effects of CA on CUMSinduced rats, with reference to fluoxetine, an established antidepressant. Fluoxetine is a selective serotonin reuptake inhibitor (SSRI) which has high selectivity for the 5-hydroxytryptamine (5-HT) transporter, which helps to modulate the concentration of serotonin in the synapses ${ }^{28}$. Fluoxetine interacts with ligands, such as channel ions $\left(\mathrm{Na}^{+}, \mathrm{K}^{+}\right.$, and $\left.\mathrm{Ca}^{2+}\right)^{29}$ and monoamine oxidases $\mathrm{A}$ and $\mathrm{B}$ (MAO$\mathrm{A}$ and $\mathrm{MAO}-\mathrm{B})^{30}$, and inhibits these proteins. Fluoxetine also affects both muscular and neuronal nicotinic receptors ${ }^{31}$. Though widely used, fluoxetine has several side effects including anxiety, sexual dysfunction, sleep disturbances, and gastrointestinal impairments $^{32}$. The anxiolytic effects of CA were evaluated through open field test (OFT) and elevated plus maze (EPM); the antidepressant effects were assessed via forced swimming test (FST) while the anti-amnesic effects were evaluated by T-maze spontaneous alternation test.

\section{MATERIALS AND METHODS}

\section{Drugs and chemicals}

Fluoxetine (Cadila Pharmaceuticals Ltd, Bhat, Ahmedabad, India) and CA extract (Reference number: AuRins-MIA-1-0, Atta-ur-Rahman Institute for Natural Product Discovery, Universiti Teknology Mara (UiTM) Puncak Alam, Selangor, Malaysia) ${ }^{33}$, were acquired from the respective sources. The extraction method for CA was performed according to the methods described by Wong et al. ${ }^{34}$. Drugs and treatments were administered in the morning between 9 a.m. to 11 a.m. The doses of fluoxetine $(10 \mathrm{mg} / \mathrm{kg})$ per dose (p.o.) (i.e. oral administration) and CA (200, 400 and $800 \mathrm{mg} / \mathrm{kg}$ ) p.o. were on the basis of previous studies ${ }^{24,35}$. Fluoxetine and CA were administered orally because it was considered the best route of drug administration for psychiatric patients $^{35}$.

\section{Animals}

Thirty-six male albino Wistar rats, aged 8-10 weeks and weighing 180-220g, were purchased from a local supplier (Bistari Ltd, Serdang, Selangor, Malaysia) and were used for this study. The rats were kept in the Animal House, Faculty of Medicine and Health Sciences Universiti Putra Malaysia and were maintained under standard laboratory conditions (12:12 $\mathrm{h}$ light/dark cycle, light on at $0700 \mathrm{~h}, 25 \pm 2^{\circ} \mathrm{C}$, relative humidity $50 \pm 10 \%$ and food and water ad libitum). The rats were allowed to acclimatize with the 
laboratory conditions for 1 week. All the non-stress exposed rats were kept 2 per cage while the stress exposed rats were kept singly or 2 per cage. The number of rats used and the protocol followed for the experiment was approved by the Institutional Animal Care and Use Committee, Universiti Putra Malaysia, on $23^{\text {rd }}$ November 2018, with project identification code UPM/IACUC/AUP-R078/2018.

\section{CUMS procedure}

CUMS was applied for 8 weeks. The rats were subjected to various psychosocial and environmental stressors, as previously described ${ }^{5,36,37}$ with minor modifications. The rats of the control group were left in their home cages except during the usual general handling and cleaning process. The CUMS-induced and drug-treated groups of rats were exposed to 9 different mild stressors (S) with a minimum of 2 stressors per day for 8 consecutive weeks:

S1: 24-hours of food deprivation;

S2: 24-hours of water deprivation;

S3: 5 -minutes of cold swimming (at $5^{\circ} \mathrm{C}$ );

S4: 12-hours change of cage mate;

S5: 1-minute tail pinch ( $1 \mathrm{~cm}$ from the tip of the tail);

S6: 12 -hours cage tilt (at $45^{\circ}$ );

S7: 12-hours overcrowding of cage;

S8: 12-hours of wet bedding with $200 \mathrm{~mL}$ of water; and

S9: 4-hours of physical restraint.

These stressors were randomly scheduled for 1 week and repeated throughout the experimental period. To avoid prophesy and adaptation, no single stressor was performed consecutively.

\section{Experimental design}

After one week of acclimatization, the 36 rats were randomly divided into six groups $(\mathrm{G})(\mathrm{n}=6)$ :

G1, Unstressed + normal saline (control); G2, CUMS + normal saline (model); G3, CUMS + fluoxetine (10 mg/kg) standard antidepressant (Flx); and G4-6, CUMS + CA $(200,400 \& 800 \mathrm{mg} / \mathrm{kg})$. Fluoxetine and CA were administered starting from day zero of the experiment once a day for 8 weeks. Behavioral tests were conducted starting from the $9^{\text {th }}$ week of the experiment, after $12 \mathrm{pm}$ daily. The detailed schedule of the experimental procedures are presented in Figure 1.

\section{Open field test}

The locomotor activity in rats was assessed through OFT, as described earlier ${ }^{37,38}$. The device consisted of a square-shaped Plexiglas box with open top with a dimension of $75 \mathrm{~cm}$ in length $\mathrm{x} 75 \mathrm{~cm}$ in width (as the base) and $40 \mathrm{~cm}$ in height. The inner surface of the base was subdivided by lines into 25 smaller square units $(15 \mathrm{~cm} \mathrm{x} 15 \mathrm{~cm})$, and is called the open field arena. A day before the test, rats were exposed to the device for 5 minutes to explore their novel environment for acclimatization. On the day of the test, each of the rats was placed separately at the centre of the open field arena and allowed to explore for $5 \mathrm{~min}$. The total distance covered by each rat and the number of lines crossed was recorded by a video tracking system for later use. A rat was considered to have crossed the line if all of its four paws crosses the line. The device was cleaned with $70 \%$ ethanol in water and allowed to dry between tests to avoid olfactory cues.

\section{Elevated plus maze}

The EPM test was used to assess the level of anxiety in rats $^{39}$, using their natural tendency of rats to explore open spaces ${ }^{40}$. The EPM device used for this study was previously described ${ }^{24}$. The rats were individually placed in the center of the device, and their exploratory behaviors were recorded for $5 \mathrm{~min}$. The parameters studied included the total number of entries by the rat into the open and closed arms of the device, and the time they spent at each visit to either the open arms or closed arms of the device. The time spent by the rat at the center of the device was not counted. After each trial, the maze was cleaned thoroughly with $70 \%$ ethanol and allowed to dry to eliminate any odor cues.

\section{Forced swimming test}

The FST was conducted based on the original method described by Slattery ${ }^{41}$ with slight modification. Briefly, one day prior to the test, rats were individually subjected to a pre-test session in a transparent cylinder (20 cm wide and $50 \mathrm{~cm}$ high) filled with water $\left(25^{\circ} \mathrm{C}\right)$ at a depth of $30 \mathrm{~cm}$, and left for 15 minutes for acclimatization. On the day of the test, the same procedure was repeated for 5 minutes and recorded with a video camera for later analysis. The duration of immobility was measured during the 5-minute test session. Immobility was defined as the absence of all movements, except the minor movements by the hind limbs of the rat to keep its head above the surface of the water.

\section{T-maze spontaneous alternation}

This test was conducted using a T-maze device fabricated from a dark plexiglass. The device was comprised of a long start arm (16 cm wide x $50 \mathrm{~cm}$ long) 

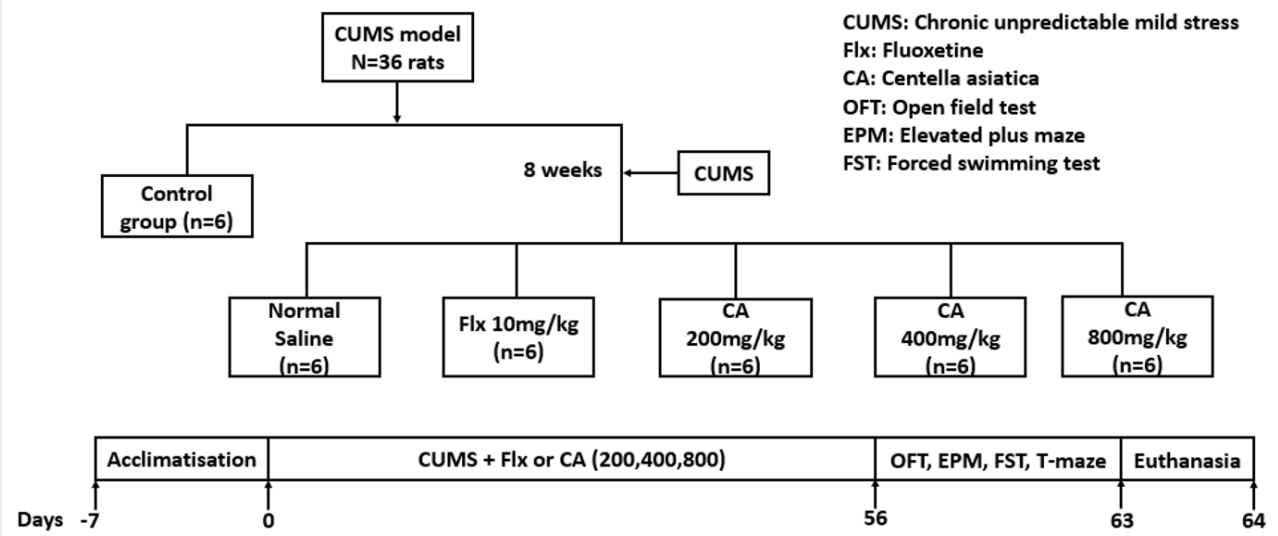

Figure 1: Experimental procedure for CUMS induction, treatments and behavioral tests, as well as abbreviations.

and two choice arms (10 cm wide x $10 \mathrm{~cm}$ long each) located perpendicularly at the top of the start arm. At the top (of that arm), a central dividing partition extended $15 \mathrm{~cm}$ into the start arm, forcing the rat to choose the left or right goal arm before reaching the convergence point ${ }^{42}$. Rats were placed individually into the start arm of the maze, facing away from the convergence point and allowed to traverse the maze and choose a direction between the two goal arms. When the rat alternated the goal arms either left or right, the correction was recorded, and when it failed, the mistake was recorded. The choice was recorded only when the four paws had entered the arm. Each rat was given 7 trials separated by $30 \mathrm{~s}$, for a possible total of 6 alternations between left and right arm choices.

\section{Measurements of biochemical parameters}

The rats were euthanized on the $64^{\text {th }}$ day of the experiments, and brain samples were collected and kept at $-80{ }^{\circ} \mathrm{C}$ for later use. Blood samples were also collected in a plain bottle, centrifuged at $5000 \mathrm{x}$ g for 5 minutes, and the serum was collected in clean eppendorf tubes.

\section{Protein concentration}

The total protein concentration of rat serum was measured using the bicinchoninic acid assay (BCA assay). Bovine serum albumin (BSA) $(1 \mathrm{mg} / \mathrm{ml})$ was used as a standard in the range of $0.01-0.1 \mathrm{mg} / \mathrm{ml}$, for comparison with the total protein.

\section{Enzyme-linked immunosorbent assay (ELISA)}

The level of cortisol from rat serum was analyzed using the quantitative sandwich ELISA technique according to the manufacturer's manual (Elabscience, USA). The optical density (OD) was then measured spectrophotometrically using a Versamax microplate reader (Molecular Devices, LLC, USA) at $450 \pm 2 \mathrm{~nm}$ wavelength. The OD values proportional to the concentrations of cortisol were calculated from the standard calibration curves generated.

\section{Statistical analysis}

Using GraphPad Prism version 6 (ISI, San Diego, CA, USA) software, the data obtained were analyzed through one way ANOVA. Tukey's post hoc comparison was used where applicable; $\mathrm{p}<0.05$ were considered significant and results were presented as mean \pm SD.

\section{RESULTS}

\section{Administration of CA attenuates CUMS- induced locomotor deficits in rats}

The OFT was used to test the locomotor activity of the rats. One way ANOVA revealed statistically significant differences in their locomotor activity [F (5, $30)=10.42, p=0.0001]$ (Figure 2). The Tukey's comparison showed statistically significant decrease in the number of lines crossed by CUMS-induced rats (39.3 $\pm 3.67, \mathrm{p}=0.006)$, when compared to control (51.1 \pm 5.34). On the other hand, statistically significant increases in number of lines crossed were observed in CUMS-induced rats co-administered with Flx (54.67 
$\pm 3.88, \mathrm{p}=0.0001), \mathrm{CA} 400(48.33 \pm 7.50, \mathrm{p}=0.023)$ and CA $800(50.67 \pm 2.73, \mathrm{p}=0.0025)$, when compared to CUMS alone $(39.33 \pm 3.67)$. No statistically significant differences were observed among the control, Flx, and CA 400 and CA 800 groups of rats.

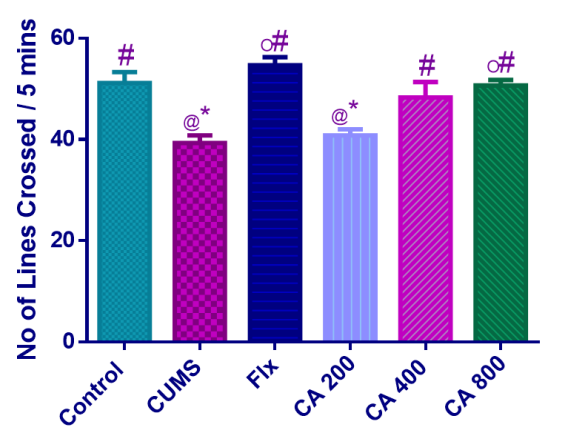

Groups of rats

Figure 2: Effects of CA on locomotor activities in CUMS-induced rats as determined by OFT. Data presented as mean $\pm S D, n=6$. ${ }^{*} p<0.05$ vs. control, $\# p<0.05$ vs. CUMS, ${ }^{\circledR} p<0.05$ vs. Flx, ${ }^{o} \mathrm{p}<0.05$ vs. 200.

\section{CA ameliorates anxiety-like behavior in CUMS-induced rats on EPM}

Rats were tested for anxiety-like behavior through EPM and the one-way ANOVA analysis revealed statistically significant differences of time spent by rats on open arms $[\mathrm{F}(5,30)=13.47, \mathrm{p}=0.0001]$. Tukey's comparison confirmed statistically significant decreases of time spent on the open arms by CUMSinduced rats $(71.67 \pm 11.5, \mathrm{p}=0.005)$ when compared to the control group of rats $(162 \pm 33.3)$. Significant increases of time spent on the open arm was also observed in CUMS-induced rats co-administered with Flx $(211.8 \pm 47.9,0.0001)$, and CA at $400 \mathrm{mg} / \mathrm{kg}$ dose $(149.9 \pm 63.85, \mathrm{p}=0.02)$ and $800(212.2 \pm 42.8, \mathrm{p}$ $=0.0001)$, when compared to CUMS alone (71.67 \pm 11.5) (Figure 3A). On the other hand, no statistically significant differences were observed in the number of entries for the open arms by all groups of rats, as shown by one way ANOVA $[\mathrm{F}(3,20)=13.47, \mathrm{p}=0.42]$ (Figure 3B).

Furthemore, one way ANOVA has revealed statistically significant differences of time spent by the rats on the closed arms $[\mathrm{F}(3,30)=11.98, \mathrm{p}=0.0001]$. Tukey's comparison confirmed statistically significant increases of time spent in the closed arms by CUMSinduced rats $(172 \pm 8.71, \mathrm{p}=0.0018)$, when compared to the control group of rats $(94.5 \pm 10.60)$.
While significant decreases of time spent on the closed arms were observed in CUMS-induced rats coadministered with Flx $(63.33 \pm 29.5, \mathrm{p}=0.0001)$, CA $400 \mathrm{mg} / \mathrm{kg}(95.17 \pm 48.55, \mathrm{p}=0.002)$, and CA 800 $\mathrm{mg} / \mathrm{kg}(64.83 \pm 31.69, \mathrm{p}=0.0001)$, when compared to CUMS alone (172 \pm 8.71$)$ (Figure 3C). Additionally, statistically significant increases of time spent in the closed arms were also observed in CA $200 \mathrm{mg} / \mathrm{kg}$ group (142 $\pm 34.92, \mathrm{p}=0.001)$ when compared to the Flx $(63.33 \pm 29.59)$. However, no statistically significant differences were observed between Flx, CA 400, and CA 800 groups of rats. Finally, one way ANOVA revealed no statistically significant differences in the number of times the rats entered into the closed arms of the maze $[\mathrm{F}(3,20)=0.265, \mathrm{p}=0.849]$ (Figure 3D).

\section{CA prevents depression-like behavior in CUMS-induced rats as determined by FST}

The protective effects of CA on depression-like behaviors in the rats were assessed via FST. One-way ANOVA showed statistically significant differences in the immobility time among the various rats groups $[\mathrm{F}(5,30)=44.43, \mathrm{p}=0.0001]$ (Figure 4). Statistically significant increases in the immobility time were observed in CUMS-induced rats $(10 \pm 10.83$, $\mathrm{p}=0.0001)$, when compared to the control group $(5 \pm 1.4)$, as revealed by Tukey's post hoc test. Whereas, statistically significant decreases of immobility time were observed in CUMS-induced rats coadministered with Flx $(3.5 \pm 1.37, \mathrm{p}=0.0001)$, CA $400(3.5 \pm 1.64, \mathrm{p}=0.0001)$ and CA $800(3.3 \pm 1.2$, $\mathrm{p}=0.0001)$, when compared to CUMS alone (10 \pm 10.83). No differences were observed between the control, Flx, CA 400, and CA 800 groups of rats.

CA attenuates learning and memory deficits in CUMS-induced rats as determined by T-maze spontaneous alternation test

The effects of CA on learning and memory abilities of the rats were assessed through T-maze spontaneous alternation test. One way ANOVA revealed statistically significant differences in the number of correct alternations among the groups of rats $[\mathrm{F}(5,30)=$ $17.76, \mathrm{p}=0.0001$ ] (Figure 5). Tukey's post hoc revealed significant decreases in the number of correct alternations in CUMS-induced rats $(50 \pm 10.95, \mathrm{p}=$ 0.0001 ) when compared to the control group of rats $(91.6 \pm 7.5)$. On the other hand, significant increases in the number of correct alternations were observed in CUMS-induced rats co-administered with Flx (88.3 $\pm 7.5, \mathrm{p}=0.0001), \mathrm{CA} 400(77.50 \pm 8.8, \mathrm{p}=0.003)$ 

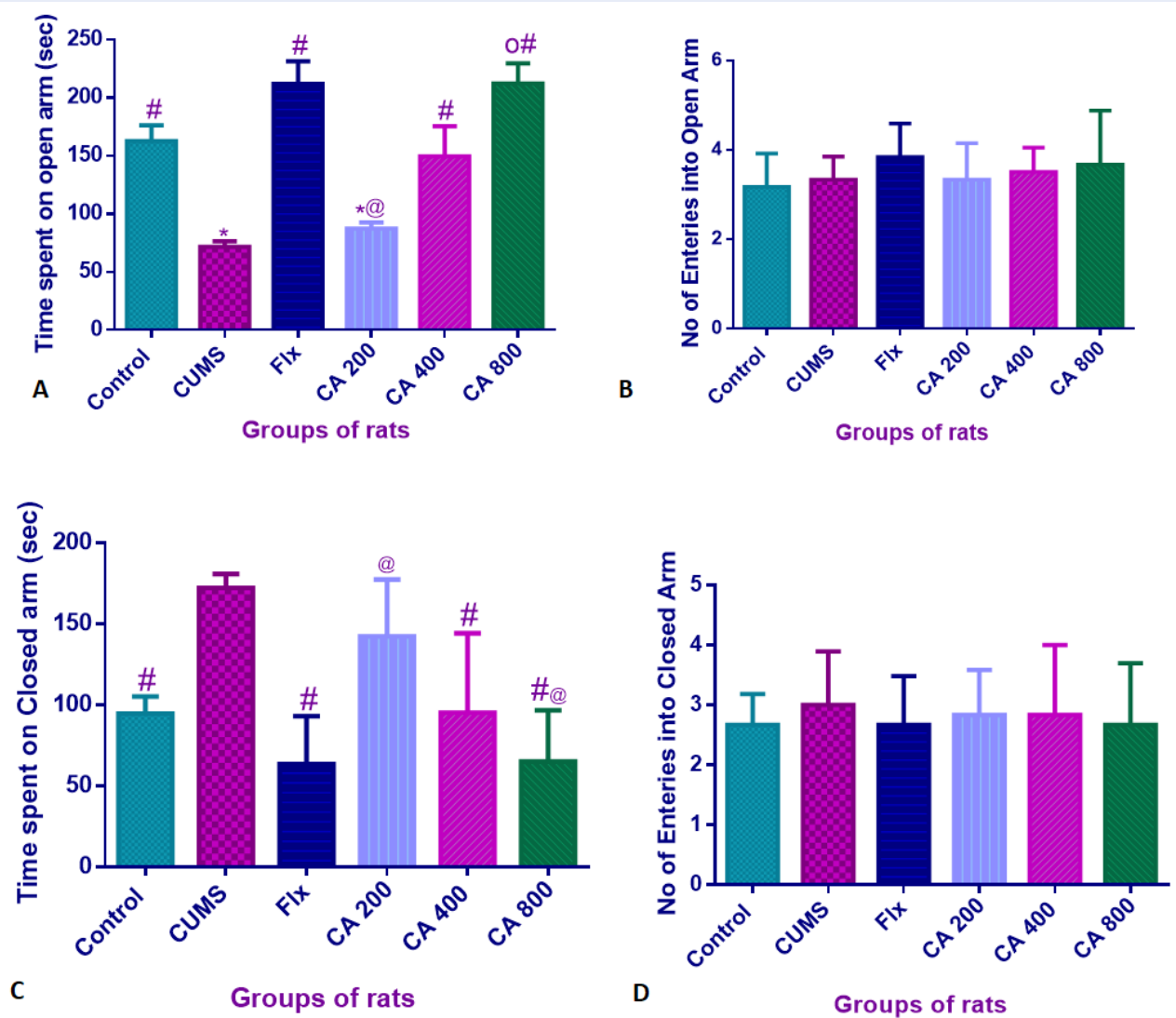

D

Groups of rats

Figure 3: Anxiolytic effects of CA on CUMS-induced rats as determined by EPM. A. Time spent on open arms; B. Number of entries into open arms; C. Time spent on closed arms; and D. Number of entries into closed arms. Data are presented as mean $\pm \mathrm{SD}, \mathrm{n}=6$. ${ }^{*} \mathrm{p}<0.05$ vs. control, ${ }^{\#} \mathrm{p}<0.05$ vs. CUMS, ${ }^{@} \mathrm{p}<0.05$ vs. Flx, ${ }^{\circ} \mathrm{p}<0.05$ vs. 200.

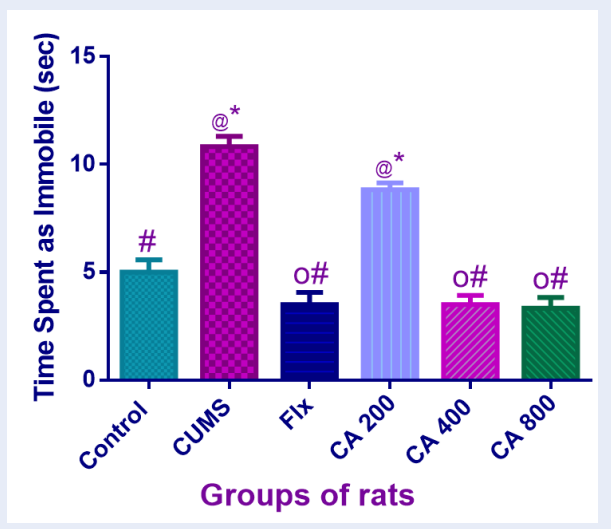

Figure 4: Antidepressants effects of CA on CUMSinduced rats as determined by FST. Data presented as mean $\pm S D, n=6$. ${ }^{*} p<0.05$ vs. control, ${ }^{\#} \mathrm{p}<0.05$ vs. CUMS, ${ }^{\circledR} \mathrm{p}<0.05$ vs. Flx, ${ }^{\circ} \mathrm{p}<0.05$ vs. 200. and CA $800(85 \pm 5.47, \mathrm{p}=0.0001)$, when compared to CUMS-induced rats alone $(50 \pm 10.95)$. No significant differences were observed among control, Flx, CA 400 and CA 800 groups of rats.

\section{CA attenuates the levels of serum cortisol in CUMS-induced rats as determined by ELISA}

The serum cortisol was evaluated in order to assess the therapeutic potentials of CA on CUMS-induced rats. One way ANOVA showed statistically significant differences in the level of serum cortisol among the groups of rats $[\mathrm{F}(5,12)=2.264, \mathrm{p}=0.0001]$ (Figure 6). The Tukey's post hoc comparison revealed significant increases of serum cortisol levels in CUMS $(36.15 \pm 1.045, \mathrm{p}=0.0001)$ and CA $200(34.64 \pm 0.72$, $\mathrm{p}=0.0001)$ groups of rats, when compared to control $(20.10 \pm 0.56)$. On the other hand, statistically significant decreases in the level of serum cortisol were observed CUMS-induced rats co-administered with 


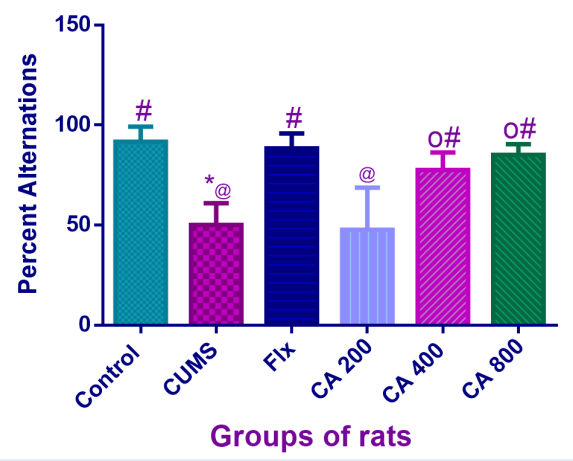

Figure 5: CA enhanced learning and memory in CUMS-induced rats as shown by T-maze test. Data presented as mean $\pm S D, n=6$. ${ }^{*} p<0.05$ vs. control, ${ }^{\#} \mathrm{p}<0.05$ vs. CUMS, ${ }^{\circledR} \mathrm{p}<0.05$ vs. Flx, ${ }^{\circ} \mathrm{p}<$ 0.05 vs. 200.
Flx $(22.08 \pm 0.507, \mathrm{p}=0.0001)$, CA $400(22.07 \pm$ $0.581, \mathrm{p}=0.0001)$ and CA $800(21.30 \pm 1.298$. p $=0.0001)$, when compared to CUMS-induced alone $(36.16 \pm 1.045)$. No statistically significant differences were seen with the Flx, control and CA (400 and 800) group of rats. Although, statistically significant different decrease of serum cortisol level was seen in CA 400 (22.07 $\pm 0.581, \mathrm{p}=0.0001)$ and CA 800 $(21.30 \pm 1.298 . \mathrm{p}=0.0001)$, when compared to CA $200(34.64 \pm 0.72)$.

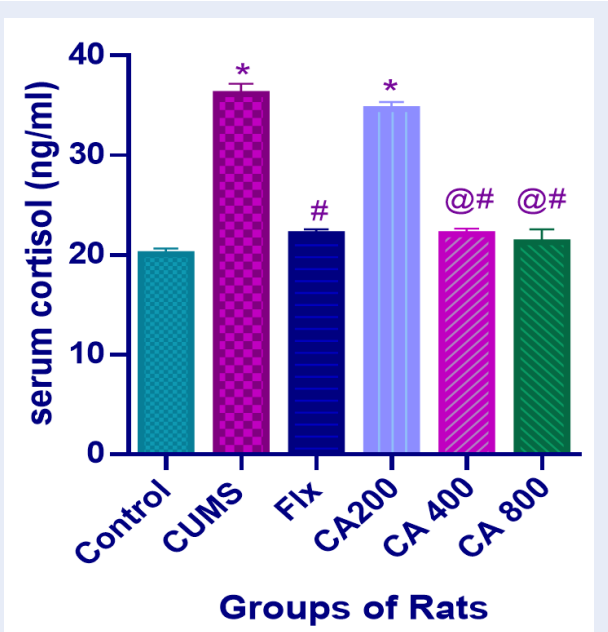

Figure 6: CA attenuates serum cortisol level in CUMS-induced rats as shown by T-maze test. Data presented as mean $\pm S D, n=6$. ${ }^{*} p<0.05$ vs. control, ${ }^{\#} p<0.05$ vs. CUMS, ${ }^{@} p<0.05$ vs. 200.

\section{DISCUSSION}

In the present study, rats subjected to CUMS were used as a model of depression to compare the effects of fluoxetine (an established antidepressant) with those of CA, which has not been previously tested in a CUMS model of depression. Major findings from this study have shown that CUMS resulted in anxiety and depression-like behaviors, as well as learning and memory impairments in rats. These behavioral changes were also parallel with the high level of serum cortisol, which is suggestive of stress induction. Administration of CA, efficiently ameliorated the anxiety, depression-like, and cognitive deficits associated with CUMS exposure.

Additionally, decreases in the level of serum cortisol were observed in the fluoxetine and CA (400 \& 800 $\mathrm{mg} / \mathrm{kg}$ ) groups of rats. Thus, fluoxetine and CA follow similar stress ameliorating pathways. These findings strongly suggest the anxiolytic, anti-depressant, and anti-amnesic effects of CA in CUMS-induced rat models. Based on the existing literature searched, this is the first report on the therapeutic properties of CA in CUMS-induced rats.

CUMS is being used widely for studying antidepressants because of its reliability ${ }^{36,43}$ and its link to many neuropsychiatric disorders, such as depression and anxiety $^{44}$. The CUMS is one of the well-established protocol for inducing depression-like behaviors in rats because it could induce stress in an unpredictable manner ${ }^{45,46}$ and can be likened to the unpredictable stressors of human life with good predictive, face and construct validity ${ }^{47}$. Therefore, a CUMS model was used to evaluate the anxiolytic, antidepressant-like, and cognitive enhancing effects of CA in this study. Nevertheless, the influence of CA on depression-like behaviors has been examined earlier in other animal models $26,27,48$

OFT is often used to quantitatively and qualitatively measure the general locomotor activities and willingness of rodents to explore their novel environments ${ }^{49}$. Therefore, OFT and actophotometers used in developing animal models assesses rodent's exploratory and locomotor behaviors ${ }^{35}$. In the present study, rats exposed to 8 weeks of CUMS had reduced locomotor activities, as demonstrated by a significant reduction of number of lines crossings in the OFT suggesting anxiety-like effect. A similar result was reported $^{37}$, where the rats exposed to CUMS covered total less distance, reduced rearing and less line crossing suggesting a change in security and emotion. Treating CUMS-induced rats with Flx 10 mg/kg 
or CA (400 and $800 \mathrm{mg} / \mathrm{kg}$ ) reversed the locomotor deficits, which is evident by the increased number of lines crossed. Previous studies have shown that treatment with fluoxetine a selective serotonin reuptake inhibitor reversed depression-related behaviors in CUMS-induced rats ${ }^{35,50}$, which is consistent with the current work. While CA at the doses of 400 and $800 \mathrm{mg} / \mathrm{kg}$ have similar effects like fluoxetine at 10 $\mathrm{mg} / \mathrm{kg}$, suggesting anxiolytic effects of CA on CUMSinduced rats.

EPM evokes conflict between the need to explore the novel area and the rodent's natural reluctance to avert vulnerable areas of the EPM (open spaces and heights $)^{26}$. Hence, EPM test was used to assess the degree of anxiety in rodent ${ }^{39}$. Enhancement of anxiety in response to CUMS exposure has been earlier reported by investigators who studied the effects of various antidepressants on anxiety ${ }^{37,51}$. In accordance with previous reports, rats exposed to CUMS showed enhanced anxiety and they spent a shorter time on open arms and longer time on the closed arms of the EPM when compared to control group of rats. Co-administration of fluoxetine $(10 \mathrm{mg} / \mathrm{kg})$ to CUMS-induced rats reversed the aforesaid anxietylike behaviors. As seen in fluoxetine group of rats, administration of CA at doses 400 and $800 \mathrm{mg} / \mathrm{kg}$ during CUMS exposure also produced anxiolytic effects which are evident from the in EPM test. In agreement with this study, a significant anxiolytic activity of ECa 233, a standardised extract of CA was reported in mice subjected to chronic immobilised stress. As the mice showed an increased frequency of visit to the open arms and spent longer time exploring the open arms $^{27}$. Similarly, asiaticoside an active phytochemical isolated from CA was reported to have anxiolytic effects in a different behavioral rat model of depres$\operatorname{sion}^{26}$.

The FST is a method widely used for the assessment of depressive-like behaviors and the evaluation of the efficacy of anti-depressive drugs in rodents ${ }^{52,53}$. It is based on the tenet that animals in an enclosed environment become immobile after an initial period of strenuous activity and that the duration of immobility decreases by effective anti-depressants agents ${ }^{53}$. As accordance with results reported from earlier studies ${ }^{36,37}$, the rats exposed to CUMS in this study also presented with depression-like behaviors as they spent longer period of immobility in the water tank when compared to the control rats. Conversely, CUMS-induced rats co-administered with fluoxetine $(10 \mathrm{mg} / \mathrm{kg})$ or CA (400 and $800 \mathrm{mg} / \mathrm{kg}$ ) do not exhibit depression-like behaviors since they showed longer mobility time in the water. Anti-depressant effects of CA and its phytochemical compound asiaticoside, were reported from different rodent models of depression $^{27,48,54}$, which are in line with the present work. Since no marked differences were observed in depressive-like behaviors between fluoxetine (10 $\mathrm{mg} / \mathrm{kg}$ ) and CA (400 \& $800 \mathrm{mg} / \mathrm{kg}$ ) treated groups of rats, it can be suggested that CA has antidepressantlike properties similar to that of fluoxetine.

The mood disorders in depressive patients are often associated with cognitive symptoms, such as difficulty in decision-making, deficits in learning and memory, and loss of cognitive flexibility ${ }^{3}$. The T-maze test could be used to assess cognitive functions in rats ${ }^{42}$, as an alternation. Whether rewarded or spontaneous the T maze test is an excellent method for identifying hippocampal dysfunction possibly even better than Morris water maze test ${ }^{55}$. Rodents exposed to CUMS exhibit cognitive dysfunctions, as confirmed by some reports of the earlier studies ${ }^{5,36}$, and the results from the present study in accordance with the previous reports. As CUMS-induced rats showed higher number of wrong alternations when compared to the control rats who scored higher number of correct alternations. However, CUMS-induced rats co-administered with fluoxetine (at $10 \mathrm{mg} / \mathrm{kg}$ ) or with CA at doses 400 or $800 \mathrm{mg} / \mathrm{kg}$ reversed the cognitive deficits that were observed in CUMS alone induced rats group. Since no significant differences were observed between fluoxetine and CA (400 \& 800) groups of rats concerning their cognitive behaviors, it can be safely concluded that CA at these doses has similar effects to fluoxetine in attenuating stress-induced cognitive deficits. Different authors have reported neuroprotective effects of CA on numerous neurodegenerative disease models and in the settings of different pathological insults $^{12,56-58}$.

The mechanistic pathways involved in depression and the actions of antidepressants are complex and multifactorial. As chronic stress can lead to dysregulation of the hypothalamic-pituitary-adrenal (HPA) axis, which is accompanied by the disproportionate generation of glucocorticoids leading to impaired hippocampal function and depression-like behaviors ${ }^{59,60}$. Antidepressants like imipramine and fluoxetine have been shown to attenuate these behavioral changes ${ }^{61}$. Elevated concentrations of cortisol have been reported in patients with depression, however, antidepressants such as fluoxetine have shown to reduce the elevated cortisol concentration ${ }^{62}$. In the present study, higher concentrations of serum cortisol were observed in rats exposed to CUMS, and these were considerably reduced by fluoxetine and CA (400 
\& 800). In this study, fluoxetine (a selective serotonin reuptake inhibitor (SSRI) was used) as a positive control. CA produced similar effects to fluoxetine, although the effects of fluoxetine are slightly higher than those of CA in most of the parameters measured. This research, therefore, speculates, that CA might work in a similar fashion to fluoxetine. Future followup studies of fluoxetine and CA will need to be conducted for further verification. This study was limited to behaviors and serum cortisol levels (when exploring the effects of CA on CUMS-exposed rats). Various other brain regions, such as the hippocampus, olfactory bulb and prefrontal cortex, are also affected by CUMS and should be explored ${ }^{63}$.

\section{CONCLUSION}

In conclusion, results from the present study showed that CA could prevent CUMS-induced behavioral changes in rats as well as reduce the concentration of cortisol. These effects of CA (at doses of $400 \& 800$ $\mathrm{mg} / \mathrm{kg}$ ) is similar to that of fluoxetine, although fluoxetine is better. This study suggests that CA might be a novel neuroprotective nutraceutical and phytochemical agent in future neurodegenerative and depression research. Molecular studies are ongoing to elucidate the probable mechanisms through which CA exerts its effects on CUMS-induced rats.

\section{ABBREVIATIONS}

ANOVA: Analysis of variance

BDNF: Brain-derived neurotrophic factor

CA3: Connus amonis 3

CA: Centella asiatica

Cm: Centimetre

CREB: cAMP-response element binding protein

CUMS: Chronic unpredictable mild stress

${ }^{\circ} \mathrm{C}$ : Degree celcius

EPM: Elevated plus maze

FLX: Fluoxetine

FST: Forced swimming test

h: Hour

HPA: Hypothalamic-pituitary-adrenal

Kg: Kilogram

Mg: Milligram

Min: Minutes

OFT: Open field test

S: Stressor

SD: Standard deviation

SSRI: Selective serotonin reuptake inhibitor

USA: United States of America

\section{COMPETING INTERESTS}

The authors report no conflicts of interest in this work.

\section{AUTHORS' CONTRIBUTIONS}

SJ, MAMM, CNMT, MIA, ZA and MTHB conceptualized and designed the work. SJ and SMC carried out the experiments and write the drafts. All authors approved the manuscript.

\section{ACKNOWLEDGMENTS}

The authors would like to acknowledge Universiti Putra Malaysia for funding this research project (Grant number GP-IPS 9535400).

\section{REFERENCES}

1. Simon GE. Social and economic burden of mood disorders. Biol Psychiatry. 2003;54(3):208-15. PMID: 12893097. Available from: 10.1016/S0006-3223(03)00420-7.

2. Rose EJ, Ebmeier KP. Pattern of impaired working memory during major depression. J Affect Disord. 2006;90(2-3):14961. PMID: 16364451. Available from: 10.1016/j.jad.2005.11.003.

3. Jarema M, Dudek D, Czernikiewicz A. [Cognitive dysfunctions in depression - underestimated symptom or new dimension?]. Psychiatr Pol. 2014;48(6):1105-16. PMID: 25717481. Available from: 10.12740/PP/31215.

4. Trivedi MH, Greer TL. Cognitive dysfunction in unipolar depression: implications for treatment. J Affect Disord. 2014;152-154:19-27. PMID: 24215896. Available from: 10. 1016/j.jad.2013.09.012.

5. Luo Y, Kuang S, Li H, Ran D, Yang J. CAMP/PKA-CREB-BDNF signaling pathway in hippocampus mediates cyclooxygenase 2induced learning/memory deficits of rats subjected to chronic unpredictable mild stress. Oncotarget. 2017;8(22):35558-72. PMID: 28415673. Available from: 10.18632/oncotarget.16009.

6. Shen J, Xu L, Qu C, Sun H, Zhang J. Resveratrol prevents cognitive deficits induced by chronic unpredictable mild stress: Sirt1/miR-134 signalling pathway regulates CREB/BDNF expression in hippocampus in vivo and in vitro. Behav Brain Res. 2018;349:1-7. PMID: 29715537. Available from: 10.1016/j.bbr. 2018.04.050.

7. Jia KK, Zheng YJ, Zhang YX, Liu JH, Jiao RQ, Pan Y, et al. Banxiahoupu decoction restores glucose intolerance in CUMS rats through improvement of insulin signaling and suppression of NLRP3 inflammasome activation in liver and brain. J Ethnopharmacol. 2017;209:219-29. PMID: 28782622. Available from: 10.1016/j.jep.2017.08.004.

8. Stockmeier CA, Mahajan GJ, Konick LC, Overholser JC, Jurjus GJ, Meltzer HY, et al. Cellular changes in the postmortem hippocampus in major depression. Biol Psychiatry. 2004;56(9):640-50. PMID: 15522247. Available from: 10.1016/ j.biopsych.2004.08.022.

9. Feng SF, Shi TY, Fan-Yang, Wang WN, Chen YC, Tan QR. Longlasting effects of chronic rTMS to treat chronic rodent model of depression. Behav Brain Res. 2012;232(1):245-51. PMID: 22537774. Available from: 10.1016/j.bbr.2012.04.019.

10. Song L, Che W, Min-Wei W, Murakami Y, Matsumoto K. Impairment of the spatial learning and memory induced by learned helplessness and chronic mild stress. Pharmacol Biochem Behav. 2006;83(2):186-93. PMID: 16519925. Available from: 10.1016/j.pbb.2006.01.004.

11. Conrad CD, Galea LA, Kuroda Y, McEwen BS. Chronic stress impairs rat spatial memory on the $Y$ maze, and this effect is blocked by tianeptine pretreatment. Behav Neurosci. 1996;110(6):1321-34. PMID: 8986335. Available from: 10. 1037/0735-7044.110.6.1321. 
12. Soumyanath A, Zhong YP, Henson E, Wadsworth T, Bishop J, Gold BG, et al. Centella asiatica Extract Improves Behavioral Deficits in a Mouse Model of Alzheimer's Disease: Investigation of a Possible Mechanism of Action. Int J Alzheimers Dis. 2012;2012:381974. PMID: 22506133. Available from: $10.1155 / 2012 / 381974$.

13. Zahara K, Bibi Y, Tabassum S. Clinical and therapeutic benefits of Centella asiatica. Pure Appl Biol. 2014;3(4):152-9. Available from: 10.19045/bspab.2014.34004.

14. Singh S, Gautam A, Sharma A, Batra A. Centella asiatica (L.): A plant with immense medicinal potential but threatened. Int J Pharm Sci Rev Res. 2010;4(2):9-17.

15. Marisa R, Assessor D, Calapai G. Assessment report on Centella asiatica (L.) Urban, herba. 2010; 2010.

16. Devkota A, Jha PK. Variation in growth of Centella asiatica along different soil composition. Bot Res Int. 2009;2(1):55-60. Available from: http://www.idosi.org/bri/2(1)09/10.pdf.

17. Zhang ZJ. Therapeutic effects of herbal extracts and constituents in animal models of psychiatric disorders. Life Sci. 2004;75(14):1659-99. PMID: 15268969. Available from: 10. 1016/j.lfs.2004.04.014.

18. Chiroma SM, Moklas MA, Norma CM, Taufik MH, Amon Z, Jagadeesan S, et al. Neuro-therapeutic Benefits of Centella asiatica on Some Neurodegenerative Diseases: A Review. Res J Pharm Biol Chem Sci. 2017;8(6):549-56.

19. Othman F. Chemical Constituents and Biological Activities of Flavonoids From Hydroponically Grown Pegaga (CENTELLA ASIATICA, LINN., URBAN) extracts. MALAYSIA; 2003.

20. Jana U, Sur TK, Maity LN, Debnath PK, Bhattacharyya D. A clinical study on the management of generalized anxiety disorder with Centella asiatica. Nepal Med Coll J. 2010;12(1):8-11. PMID: 20677602.

21. Chiroma SM, Baharuldin MTH, Taib M, Norma C, Amom Z, Jagadeesan $\mathrm{S}$, et al. Protective Effects of Centella asiatica on Cognitive Deficits Induced by D-gal/AICl3 via Inhibition of Oxidative Stress and Attenuation of Acetylcholinesterase Level. Toxics. 2019;7(2):19. Available from: 10.3390/toxics7020019.

22. Chiroma SM, Baharuldin MTH, Taib M, Norma C, Amom Z, Jagadeesan S, et al. Centella asiatica Protects d-Galactose/AICI3 Mediated Alzheimer's Disease-Like Rats via PP2A/GSK-3\$ $\beta$ \$ Signaling Pathway in Their Hippocampus. International journal of molecular sciences. 2019;20(8):1871. Available from: 10.3390/ijms20081871.

23. Rao SB, Chetana M, Devi PU. Centella asiatica treatment during postnatal period enhances learning and memory in mice. Physiol Behav. 2005;86(4):449-57. PMID: 16214185. Available from: 10.1016/j.physbeh.2005.07.019.

24. Chiroma SM, Baharuldin MTH, Taib CNM, Amom Z, Jagadeesan S, Adenan Ml, et al. Protective effect of Centella asiatica against $\mathrm{D}$-galactose and aluminium chloride induced rats: behavioral and ultrastructural approaches. Biomed Pharmacother. 2019;109(109):853-64. PMID: 30551539. Available from: 10.1016/j.biopha.2018.10.111.

25. Chen SW, Wang WJ, Li WJ, Wang R, Li YL, Huang YN, et al Anxiolytic-like effect of asiaticoside in mice. Pharmacol Biochem Behav. 2006;85(2):339-44. PMID: 17059844. Available from: $10.1016 /$ j.pbb.2006.08.017.

26. Wijeweera P, Arnason JT, Koszycki D, Merali Z. Evaluation of anxiolytic properties of Gotukola-(Centella asiatica) extracts and asiaticoside in rat behavioral models. Phytomedicine. 2006;13(9-10):668-76. PMID: 16488124. Available from: 10 1016/j.phymed.2006.01.011.

27. Wanasuntronwong A, Tantisira $\mathrm{MH}$, Tantisira B, Watanabe $\mathrm{H}$. Anxiolytic effects of standardized extract of Centella asiatica (ECa 233) after chronic immobilization stress in mice. J Ethnopharmacol. 2012;143(2):579-85. PMID: 22841896. Available from: 10.1016/j.jep.2012.07.010.

28. Fuller RW, Wong DT, Robertson DW. Fluoxetine, a selective inhibitor of serotonin uptake. Med Res Rev. 1991;11(1):17-34. PMID: 1994152. Available from: 10.1002/med.2610110103.

29. Deák F, Lasztóczi B, Pacher P, Petheö GL, Kecskeméti V, Spät A. Inhibition of voltage-gated calcium channels by fluoxe- tine in rat hippocampal pyramidal cells. Neuropharmacology. 2000;39(6):1029-36. PMID: 10727713. Available from: 10.1016/S0028-3908(99)00206-3.

30. Leonardi ET, Azmitia EC. MDMA (ecstasy) inhibition of MAO type $A$ and type $B$ : comparisons with fenfluramine and fluoxetine (Prozac). Neuropsychopharmacology. 1994;10(4):231-8. PMID: 7945733. Available from: 10.1038/npp.1994.26.

31. García-Colunga J, Awad JN, Miledi R. Blockage of muscle and neuronal nicotinic acetylcholine receptors by fluoxetine (Prozac). Proc Natl Acad Sci USA. 1997;94(5):2041-4. PMID: 9050901. Available from: 10.1073/pnas.94.5.2041.

32. Brambilla P, Cipriani A, Hotopf M, Barbui C. Side-effect profile of fluoxetine in comparison with other SSRIs, tricyclic and newer antidepressants: a meta-analysis of clinical trial data. Pharmacopsychiatry. 2005;38(2):69-77. PMID: 15744630. Available from: 10.1055/s-2005-837806.

33. Yeo NABMY, Muthuraju S, Wong JH, Mohammed FR, Senik $\mathrm{MH}$, Zhang J, et al. Hippocampal amino-3-hydroxy-5-methyl4-isoxazolepropionic acid GluA1 (AMPA GluA1) receptor subunit involves in learning and memory improvement following treatment with Centella asiatica extract in adolescent rats. Brain Behav. 2018;8(9):e01093. PMID: 30105867. Available from: 10.1002/brb3.1093.

34. Wong JH, Muthuraju S, Reza F, Senik MH, Zhang J, Yeo NAMY, et al. Differential expression of entorhinal cortex and hippocampal subfields $\alpha$-amino-3-hydroxy-5-methyl-4isoxazolepropionic acid (AMPA) and N-methyl-D-aspartate (NMDA) receptors enhanced learning and memory of rats following administration of Centella asiatica. Biomed Pharmacother. 2019;110(110):168-80. PMID: 30469081. Available from: 10.1016/j.biopha.2018.11.044.

35. Fernandes J, Gupta GL. N-acetylcysteine attenuates neuroinflammation associated depressive behavior induced by chronic unpredictable mild stress in rat. Behav Brain Res. 2019;364:356-65. PMID: 30772427. Available from: 10.1016/j. bbr.2019.02.025.

36. Zhao Y, Wang Q, Jia M, Fu S, Pan J, Chu C, et al. (+)Sesamin attenuates chronic unpredictable mild stressinduced depressive-like behaviors and memory deficits via suppression of neuroinflammation. J Nutr Biochem. 2019;64:61-71. PMID: 30445417 . Available from: 10.1016/j.jnutbio.2018.10.006.

37. Tong J, Zhou Z, Qi W, Jiang S, Yang B, Zhong Z, et al. Antidepressant effect of helicid in chronic unpredictable mild stress model in rats. Int Immunopharmacol. 2019;67:13-21. PMID: 30530165. Available from: 10.1016/j.intimp.2018.11.052.

38. Chiroma SM, Moklas MAM, Taib CNM, Baharuldin MT, Amon Z. d-galactose and aluminium chloride induced rat model with cognitive impairments. Biomed Pharmacother. 2018;103(April):1602-8. PMID: 29864948. Available from: 10.1016/j.biopha.2018.04.152.

39. Chioca LR, Ferro MM, Baretta IP, Oliveira SM, Silva CR, Ferreira J, et al. Anxiolytic-like effect of lavender essential oil inhalation in mice: participation of serotonergic but not GABAA/benzodiazepine neurotransmission. J Ethnopharmacol. 2013;147(2):412-8. PMID: 23524167. Available from: 10.1016/j.jep.2013.03.028.

40. Pellow S, Chopin P, File SE, Briley M. Validation of open:closed arm entries in an elevated plus-maze as a measure of anxiety in the rat. J Neurosci Methods. 1985;14(3):149-67. PMID: 2864480. Available from: 10.1016/0165-0270(85)90031-7.

41. Slattery DA, Cryan JF. Using the rat forced swim test to assess antidepressant-like activity in rodents. Nat Protoc 2012;7(6):1009-14. PMID: 22555240. Available from: 10.1038/ nprot.2012.044.

42. Deacon RM, Rawlins JN. T-maze alternation in the rodent. Nat Protoc. 2006;1(1):7-12. PMID: 17406205. Available from: 10. 1038/nprot.2006.2.

43. Pekala K, Budzynska B, Biala G. Utility of the chronic unpredictable mild stress model in research on new antidepressants. Curr Issues Pharm Med Sci. 2014;27(2):97-101. Avail- 
able from: 10.2478/cipms-2014-0022.

44. Karson A, Demirtaş T, Bayramgürler D, Balci F, Utkan T. Chronic administration of infliximab (TNF- $\alpha$ inhibitor) decreases depression and anxiety-like behaviour in rat model of chronic mild stress. Basic Clin Pharmacol Toxicol. 2013;112(5):335-40. PMID: 23167806. Available from: 10.1111/bcpt.12037.

45. Wang GL, Wang YP, Zheng JY, Zhang LX. Monoaminergic and aminoacidergic receptors are involved in the antidepressantlike effect of ginsenoside Rb1 in mouse hippocampus (CA3) and prefrontal cortex. Brain Res. 2018;1699:44-53. PMID: 29802841. Available from: 10.1016/j.brainres.2018.05.035.

46. Gupta GL, Fernandes J. Protective effect of Convolvulus pluricaulis against neuroinflammation associated depressive behavior induced by chronic unpredictable mild stress in rat. Biomed Pharmacother. 2019;109(109):1698-708. PMID: 30551424. Available from: 10.1016/j.bbr.2019.02.025.

47. Willner P. The chronic mild stress (CMS) model of depression: History, evaluation and usage. Neurobiol Stress. 2016;6:78-93. PMID: 28229111. Available from: 10.1016/j.ynstr.2016.08.002.

48. Kalshetty $P$, Aswar U, Bodhankar S, Sinnathambi A, Mohan $\mathrm{V}$, Thakurdesai P. Antidepressant effects of standardized extract of Centella asiatica $L$ in olfactory bulbectomy model. Biomed Aging Pathol. 2012;2(2):48-53. Available from: 10. 1016/j.biomag.2012.03.005.

49. Stanford SC. The open field test: reinventing the wheel. J Psychopharmacol. 2007;21(2):134-5. PMID: 17329288. Available from: 10.1177/0269881107073199.

50. Mu RH, Fang XY, Wang SS, Li CF, Chen SM, Chen XM, et al. Antidepressant-like effects of standardized gypenosides: involvement of brain-derived neurotrophic factor signaling in hippocampus. Psychopharmacology (Berl). 2016;233(17):3211-21. PMID: 27385417. Available from: 10.1007/s00213-016-4357-z.

51. El-Fattah AAA, Fahim AT, Sadik NA, Ali BM. Resveratrol and dimethyl fumarate ameliorate depression-like behaviour in a rat model of chronic unpredictable mild stress. Brain Res. 2018;1701(June):227-36. PMID: 30244113. Available from: 10.1016/j.brainres.2018.09.027.

52. Álvarez Suárez $P$, Banqueri $M$, Vilella $M$, Méndez $M$, Arias JL. The effect of recording interval length on behavioral assessment using the forced swimming test. Rev Iberoam Psicol y Salud. 2015;6(2):90-5. Available from: 10.1016/j.rips.2015.04. 004.

53. Katz RJ, Roth KA, Carroll BJ. Acute and chronic stress effects on open field activity in the rat: implications for a model of depression. Neurosci Biobehav Rev. 1981;5(2):247-51. PMID: 7196554. Available from: 10.1016/0149-7634(81)90005-1.
54. Luo L, Liu XL, Mu RH, Wu YJ, Liu BB, Geng D, et al. Hippocampal BDNF signaling restored with chronic asiaticoside treatment in depression-like mice. Brain Res Bull. 2015;114:62-9. PMID: 25857945. Available from: 10.1016/j.brainresbull.2015.03.006.

55. Deacon RM, Rawlins JN. Hippocampal lesions, speciestypical behaviours and anxiety in mice. Behav Brain Res. 2005;156(2):241-9. PMID: 15582110. Available from: 10.1016/ j.bbr.2004.05.027.

56. Gray NE, Zweig JA, Murchison C, Caruso M, Matthews DG, Kawamoto $C$, et al. Centella asiatica attenuates $A \beta$-induced neurodegenerative spine loss and dendritic simplification. Neurosci Lett. 2017;646:24-9. PMID: 28279707. Available from: 10.1016/j.neulet.2017.02.072.

57. Prakash A, Kumar A. Mitoprotective effect of Centella asiatica against aluminum-induced neurotoxicity in rats: possible relevance to its anti-oxidant and anti-apoptosis mechanism. Neurol Sci. 2013;34(8):1403-9. PMID: 23224641. Available from: $10.1007 / \mathrm{s} 10072-012-1252-1$.

58. Kumar MHV, Gupta YK. Effect of Centella asiatica on cognition and oxidative stress in an intracerebroventricular streptozotocin model of Alzheimer's disease in rats. Clin Exp Pharmacol Physiol. 2003;30(5-6):336-42. PMID: 12859423. Available from: 10.1046/j.1440-1681.2003.03842.x.

59. Mahar I, Bambico FR, Mechawar N, Nobrega JN. Stress, serotonin, and hippocampal neurogenesis in relation to depression and antidepressant effects. Neurosci Biobehav Rev. 2014;38:173-92. PMID: 24300695. Available from: 10.1016/ j.neubiorev.2013.11.009.

60. Li HY, Zhao YH, Zeng MJ, Fang F, Li M, Qin TT, et al. Saikosaponin $D$ relieves unpredictable chronic mild stress induced depressive-like behavior in rats: involvement of HPA axis and hippocampal neurogenesis. Psychopharmacology (Berl). 2017;:

61. Zhang Y, Ge JF, Wang FF, Liu F, Shi C, Li N. Crassifoside H improve the depressive-like behavior of rats under chronic unpredictable mild stress: possible involved mechanisms. Brain Res Bull. 2017;135:77-84. PMID: 28970041. Available from: 10.1016/j.brainresbull.2017.09.015.

62. Chau DT, Rada PV, Kim K, Kosloff RA, Hoebel BG. Fluoxetine alleviates behavioral depression while decreasing acetylcholine release in the nucleus accumbens shell. Neuropsychopharmacology. 2011;36(8):1729-37. PMID: 21525864. Available from: $10.1038 / n p p .2011 .54$

63. François BL, Soo J, Millar AM, Daigle M, Guisquet AML, Leman $S$, et al. Chronic mild stress and antidepressant treatment alter 5-HT1A receptor expression by modifying DNA methylation of a conserved Sp4 site. Neurobiol Dis. 2015;82:332-41. PMID: 26188176. Available from: 10.1016/j.nbd.2015.07.002. 